\title{
Disposition of $2,2^{\prime}, 4,44^{\prime}, 5,5^{\prime}$-hexabromodiphenyl ether (BDE153) nd its interaction with other PBDEs in rodents
}

\author{
J. M. Sanders ${ }^{1,2}$, E. H. Lebetkin ${ }^{1}$, L.-J. Chen ${ }^{1}$, and L. T. Burka ${ }^{1}$ \\ ${ }^{1}$ Laboratory of Pharmacology and Chemistry, National Toxicology Program, National Institute of \\ Environmental Health Sciences, Research Triangle Park, NC 27709, USA \\ ${ }^{2}$ Department of Environmental and Molecular Toxicology, North Carolina State University, Raleigh, \\ NC 27695, USA
}

\section{Abstract}

1. The disposition of the ${ }^{14} \mathrm{C}$-labeled polybrominated diphenyl ether (PBDE), $2,2^{\prime}, 4,4^{\prime}, 5,5^{\prime}$ hexaBDE (BDE153) was investigated in rodents following single and multiple doses and in a mixture with radiolabeled 2,2',4,4'-tetraBDE (BDE47) and 2,2',4,4',5-pentaBDE (BDE99).

2. In single exposure studies, there was little or no effect of dose on BDE153 disposition in male rats in the range of $1-100 \mu \mathrm{mol} / \mathrm{kg}$. No major sex or species differences in the in vivo fate of BDE153 were detected. BDE153 was: 1) approximately $70 \%$ absorbed in rats or mice following gavage. 2) retained in tissues. 3 ) poorly metabolized and slowly excreted.

3. Mixture studies indicated that, relative to each other, more BDE47 was distributed to adipose tissue, more BDE153 accumulated in liver, and BDE99 was metabolized to the greatest extent. BDE153 was probably retained in liver due to minimal metabolism and elimination after "first pass" distribution to the tissue following gavage.

\section{Keywords}

Polybrominated diphenyl ethers; PBDE; metabolism and disposition; persistent organic pollutants

\section{Introduction}

Polybrominated diphenyl ethers (PBDEs), primarily used as flame retardants, are highly lipophilic, persistent in the environment, and accumulate in biota (reviewed in de Wit 2002). Tetra-, penta-, and hexaBDEs, major congeners detected in mammalian tissues and fluids, are components of commercial flame retardant products such as Great Lakes DE-71'TM (DE71) and Bromkal 70-5DE ${ }^{\text {TM }}$ (BK70) (Sjödin et al. 1998; de Wit 2002; Chen et al. 2006a). The DE71 used in previous studies in our laboratory contained (by peak area as determined by GC/MS)

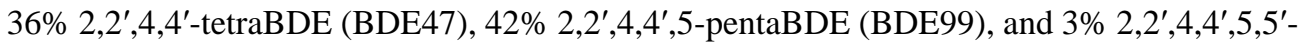
hexaBDE (BDE153) (Sanders et al. 2005); similar to respective amounts of the three congeners (37, 35, and 4\%) in BK70 (Sjödin et al. 1998). These, as well as 2,2',4,4',6-pentaBDE


DE71 (Sjödin et al. 1998; Chen et al. 2006a), and are the prevalent congeners detected in human

Correspondence: J.M. Sanders, NIEHS, P.O. Box 12233, Research Triangle Park, NC 27709, USA. Fax: 919-541-1872. sander10@niehs.nih.gov. 
tissue and fluid samples (Hites 2004). All five PBDEs have increased over time in some populations (Meironyté et al. 1999; Sjödin et al. 2004).

Data are limited for adequate risk assessment of PBDE exposure to humans. Flame retardant products containing lower molecular weight PBDEs have shown the ability to induce CYP1A1 in rodents (von Meyerinck et al. 1990; Fowles et al. 1994; Zhou et al. 2001, 2002); therefore, the possibility of PBDE-mediated dioxin-like toxicity has been of concern. However, we have demonstrated that polybrominated dibenzodioxins and furans detected in PBDE preparations are likely responsible for dioxin-like properties observed in prior studies of these chemicals in rodents (Sanders et al. 2005). Conversely, our work showed that BDE47, BDE99, and BDE153 up-regulated $C Y P 2 B$ and $C Y P 3 A$ gene expression in rats within the same order of magnitude as non-dioxin-like PCB153. These data support conclusions that lower molecular weight PBDEs are phenobarbital (PB)-like enzyme inducers and toxicity observed in rodents exposed to pure PBDEs may be categorized by aryl hydrocarbon receptor (AhR)-independent pathways.

A fraction of the human population may have tissue concentrations of lower molecular weight PBDEs near those associated with reproductive effects in rats and developmental neurotoxicity in mice (McDonald 2005). Accumulation of a PBDE in tissues is just one parameter of its in vivo fate that may influence toxicity following exposure. Others are the extent, rates, and routes of absorption, metabolism, and excretion, as well as specificity of tissue distribution. Further, potential toxicity of PBDEs may vary due to differences in, or interactions between, the in vivo fates of individual congeners following exposure to these chemicals in mixtures.

Our laboratory has previously investigated the disposition and metabolism of BDE47 and BDE99 in rodents (Sanders et al. 2006; Chen et al. 2006b). The results of those studies demonstrated quantitative differences in the in vivo fates of a tetra- and pentaBDE; therefore, the present work extends those investigations to a hexaBDE component of the BK70 and DE71 mixtures. In these studies, we have searched for effects on the disposition and metabolism of BDE153 in rodents due to sex, species, dose, or repeated administration, and have investigated differences in the in vivo fates of BDE47, BDE99, and BDE153 when administered together as a mixture.

\section{Materials and Methods}

\section{Dosing solutions}

Radiolabeled (phenyl- ${ }^{14} \mathrm{C}$ ) 2,2',4,4'-tetraBDE (BDE47), 2,2',4,4',5-pentaBDE (BDE99), and 2,2',4,4',5,5'-hexaBDE (BDE153) were obtained from NEN Life Science Products (Boston, MA). Specific activities and radiochemical purities were $36.5 \mathrm{mCi} / \mathrm{mol}$ and $99 \%$ for BDE47, $35.6 \mathrm{mCi} / \mathrm{mmol}$ and $98 \%$ for BDE99, and $27.8 \mathrm{mCi} / \mathrm{mmol}$ and $96 \%$ for BDE153. Unlabeled BDE47, BDE99, and BDE153 were obtained from Cerilliant (Round Rock, TX). Purity of the unlabeled material was ca. 99, 96, and 96\% for BDE47, BDE99, and BDE153, respectively (Sanders et al. 2005). Dosing solutions for the oral administration of BDE153 of either 1, 10, or $100 \mu \mathrm{mol} / \mathrm{kg}(0.6,6.4$, or $64 \mathrm{mg} / \mathrm{kg})$ were made by adding BDE153 dissolved in acetone to corn oil, then evaporating the acetone under a steady stream of nitrogen. Unlabeled BDE153 was added as appropriate and dissolved by heating the corn oil. The final volumes of dosing solutions were adjusted to deliver $5 \mathrm{ml} / \mathrm{kg}$ to rats and $10 \mathrm{ml} / \mathrm{kg}$ to mice. An aqueous-based dosing solution $(1 \mu \mathrm{mol} / \mathrm{kg})$ was made for iv administration $(1 \mathrm{ml} / \mathrm{kg})$ of BDE153 by adding radiolabeled chemical dissolved in acetone to Cremophor EL (Sigma St. Louis, MO), evaporating the acetone with nitrogen, then adding ethanol and water for a final ratio of 1:1:3 Cremophor EL:ethanol:water (v/v/v). An equimolar mixture of BDE47, BDE99, and BDE153 ( $1 \mu \mathrm{mol} / \mathrm{kg}$ of each congener) was prepared in corn oil as previously described for delivery by gavage at $5 \mathrm{ml} / \mathrm{kg}$. Dosing solutions of $1 \mu \mathrm{mol} / \mathrm{kg}$ of radiolabeled BDE47 or BDE99 were made as described in Sanders et al. (2006) and Chen et al. (2006b). BDE47, BDE99, and BDE153 
were administered at ca. 28,36 , and $37 \mu \mathrm{Ci} / \mathrm{kg}$, respectively, except for BDE153 administered at $2.8 \mu \mathrm{Ci} / \mathrm{kg} /$ day to rats receiving 10 consecutive daily doses.

\section{Animals}

Male (209-283 g) and female (157-171g) F344 rats were obtained from Charles River Laboratories in Portage, MI. Male (21-24 g) and female (17-19g) B6C3F1 mice were obtained from Taconic (Germantown, NY). The age range of animals was ca. 2-4 months. Procedures involving animals were carried out in accordance with institutional guidelines.

\section{Disposition experiments}

Rats and mice received single doses of $1 \mu \mathrm{mol} / \mathrm{kg}$ by gavage to investigate species- or sexrelated differences in BDE153 metabolism and disposition. Dose-response studies were characterized in male rats by administering single doses of 1,10 , or $100 \mu \mathrm{mol} / \mathrm{kg}$. Single iv injections of $1 \mu \mathrm{mol} / \mathrm{kg}$ were administered into tail veins of male rats and mice for estimating the extent of absorption of BDE153 following oral administration of a similar dose. Accumulation of BDE153 in tissues and effects on BDE153 disposition and metabolism following repeated exposure were investigated by administering $1 \mu \mathrm{mol} / \mathrm{kg}$ by gavage to male rats for 1,3 , and 10 consecutive days. Other male rats received the prepared radiolabeled mixture of equimolar doses $(1 \mu \mathrm{mol} / \mathrm{kg})$ of BDE47, BDE99, and BDE153 for 1 or three days by gavage. Comparisons were made to animals receiving similar doses of BDE47, BDE99, or BDE153, dosed here or in experiments described in Sanders et al. (2006) and Chen et al. (2006b). All treated animals were placed into individual metabolism cages for the collection of cumulative urine and feces $24 \mathrm{~h}$ following each dose. Food (NIH \#31) and water were provided for ad libitum consumption. All animals in these studies were euthanized with $\mathrm{CO}_{2}$ and necropsied $24 \mathrm{~h}$ following a single dose or the last of consecutive doses. An exception was a group of rats euthanized and necropsied 10 days after receiving a single dose of $1 \mu \mathrm{mol} / \mathrm{kg}$ of BDE153. Cumulative urine and feces samples were collected from that group every $24 \mathrm{~h}$ throughout the 10 day holding period. Aliquots of urine (20-50 $\mu$ l) in Ecolume (ICN, Costa Mesa, CA) were analyzed in a Beckman Coulter (Fullerton, CA) model LS6500 model liquid scintillation counter (LSC) for determination of ${ }^{14} \mathrm{C}$ content. Feces and tissue aliquots (up to $100 \mathrm{mg}$ ) were combusted in a Packard model 307 biological tissue oxidizer (PerkinElmer Life and Analytical Sciences, Boston, MA) for measurement of ${ }^{14} \mathrm{C}$ content in the LSC. Fecal excretion data include BDE153-derived radioactivity present in the large intestine at time of sacrifice. All tissue weights were determined gravimetrically, except blood, adipose tissue, skin, and muscle, estimated at $8,11,16$, and $50 \%$ total body weight, respectively. Disposition data presented in the text represent the mean \pm SD of 3-5 animals.

\section{Procedure for collecting bile}

Bile was collected from BDE153-treated rats using the method described by Sanders et al. (2006). Briefly, each rat $(\mathrm{n}=2)$ was anesthetized, the bile duct was isolated and ligated, and bile was collected for $4 \mathrm{~h}$ following iv administration of $1 \mu \mathrm{mol} \mathrm{BDE} 153 / \mathrm{kg} / \mathrm{ml}$ into a tail vein. Following collection, the ${ }^{14} \mathrm{C}$ in bile was counted in the LSC and characterized by HPLC (system \#2). Rats were euthanized with $\mathrm{CO}_{2} 4 \mathrm{~h}$ post-dosing.

\section{Extraction of ${ }^{14} \mathrm{C}$ from excreta and tissues}

Adipose tissue, liver, and cumulative $24 \mathrm{~h}$ feces $(\leq 1 \mathrm{~g})$ collected after one and three doses of $1 \mu \mathrm{mol} \mathrm{BDE} 153 / \mathrm{kg}$ alone or in a mixture with BDE47 and BDE99; as well as feces, adipose tissue, and liver samples obtained from male rats treated with similar doses of BDE47 or BDE99 here or in previous experiments described in Sanders et al. (2005) and Chen et al. (2006b), were homogenized in 1-3 $\mathrm{ml}$ of $50 \mathrm{mM}$ sodium phosphate buffer (pH 7) and 10-20 $\mathrm{ml}$ of a 95:5 (v/v) mixture of hexane/isoamyl alcohol. The solution was centrifuged at 10,000 
$\mathrm{g}$ for $5 \mathrm{~min}$, then the lower tissue homogenate layer was frozen in a dry ice:acetone bath. The upper organic solvent layer was removed and the ${ }^{14} \mathrm{C}$ content determined ( $20-50 \mu 1$ aliquots). The procedure was repeated twice more. Aliquots $(50 \mu \mathrm{l})$ of the remaining tissue homogenate were oxidized and the ${ }^{14} \mathrm{C}$ content was determined by scintillation counting. The initial solvent layer was evaporated in a glass vial under a steady stream of $\mathrm{N}_{2}$ and the residue was resuspended in a volume of 95:5 hexane:isoamyl alcohol not exceeding $0.5 \mathrm{ml}$. Approximately $0.5 \mathrm{ml}$ of acetonitrile was added prior to transfer of the sample to a plastic microcentrifuge tube for further concentration under $\mathrm{N}_{2}$ to a final volume of $\leq 0.5 \mathrm{ml}$. Each sample was centrifuged at 16,000 $\mathrm{g}$ for $2 \mathrm{~min}$ and injected into HPLC system \#2 described below. An appreciable amount of ${ }^{14} \mathrm{C}$ was not extracted from liver of BDE99-treated rats with hexane:isoamyl alcohol. Therefore additional washes of these samples were made with $5 \mathrm{ml}$ each of methanol until the supernatant contained no more than twice background radioactivity. The remaining pellets were solubilized overnight in $2 \mathrm{ml}$ of $2 \mathrm{~N} \mathrm{NaOH}$ at $37^{\circ} \mathrm{C}$ and the protein content was determined using the Bio-Rad (Hercules, $\mathrm{CA}$ ) protein assay based on the Bradford dye-binding procedure. Aliquots of the solubilized pellet $(20 \mu \mathrm{l})$ were analyzed in the LSC for ${ }^{14} \mathrm{C}$ content. The methanolic extracts were concentrated to dryness using a SpeedVac Concentrator (ThermoSavant, Holbrook, NY), resuspended and pooled in a total volume of $1 \mathrm{ml}$ methanol, concentrated under $\mathrm{N}_{2}$ to a lesser volume, then analyzed by HPLC. Data derived from experiments described in this section are presented in the text as the mean \pm S.D. for ${ }^{14} \mathrm{C}$ recovered from 1 tissue or excreta sample from each of 3-5 animals/group.

\section{Analytical HPLC methods}

PBDE congeners and metabolites were resolved using either of two HPLC systems. System \#1 utilized a mobile phase consisting of solvent A: $0.1 \%$ trifluoroacetic acid in $\mathrm{H}_{2} \mathrm{O}$ and solvent B: acetonitrile, at a flow rate of $1.5 \mathrm{ml} / \mathrm{min}$. A linear gradient of 1:1 A:B to $100 \% \mathrm{~B}$ in $30 \mathrm{~min}$ was used. System hardware consisted of dual Waters Corp. (Milford, MA) model 510 pumps, controlled by Empower ${ }^{\mathrm{TM}}$ software, a Radiomatic (PerkinElmer Life and Analytical Sciences, Boston, MA) model 280 radiochemical detector, a Waters model 481 spectrophotometer with wavelength monitored at $254 \mathrm{~nm}$, and a Waters $3.9 \times 300 \mathrm{~mm} \mu$ Bondapak $\mathrm{C}_{18} 10 \mu \mathrm{m}$ column. HPLC system \#2 consisted of a Beckman System Gold module 126 solvent pump, a Beckman module 168 photodiode array detector, and a Metachem (Torrance, CA) $4.6 \times 250 \mathrm{~mm}$ Inertsil $\mathrm{C}_{18} 5 \mu \mathrm{m}$ column. Radiochemical detection was achieved using an INIUS (Tampa, FL) $\beta$-RAM flow detector. The mobile phase and flow rate were the same as described above; however, a linear gradient of $100 \%$ A to $100 \%$ B over 30 min was used. Conditions were held at 100\% B for an additional $10 \mathrm{~min}$.

\section{Statistical analysis}

Statistical analyses were performed using Student's t-test or one-way ANOVA followed by the Tukey-Kramer test for pair-wise comparisons (JMP Statistical Software, SAS Institute Inc., Cary, NC). Values were considered to be significantly different at $\mathrm{p}<0.05$.

\section{Results}

BDE153 is one of the five major PBDEs in DE71, but relative to BDE47 and BDE99 is a minor component of the mixture (Figure 1). Administration of BDE153 in the range of 1-100 $\mu \mathrm{mol} /$ $\mathrm{kg}$ produced no overt signs of toxicity in any animals used in the present studies. BDE153 was absorbed following oral administration to rats and mice as demonstrated by distribution of BDE153-derived radioactivity to major tissues (Table I). However, less than complete absorption of dose in gavaged animals was inferred by the observation of much less excretion of ${ }^{14} \mathrm{C}$ in feces of iv-injected animals (Table I). This supposition was supported by the fact that most of the ${ }^{14} \mathrm{C}$ excreted in feces of gavaged rats consisted of parent chemical (see below). Further, only a negligible amount of the BDE153 excreted in feces of gavaged rats appeared 
to have been absorbed, as evidenced by minimal excretion of ${ }^{14} \mathrm{C}$ in bile (less than $0.5 \%$ dose within $4 \mathrm{hr}$ ), all as parent chemical (data not shown). Overall, the data indicated that approximately $70 \%$ of a single po dose of $1 \mu \mathrm{mol} / \mathrm{kg}$ was absorbed in either rodent species.

Based on tissue volume, adipose, skin, and muscle contained the most BDE153-derived radioactivity following absorption of dose. There were no significant differences in $\%$ dose distributed to corresponding tissues of gavaged male and female rats. However, significantly more ${ }^{14} \mathrm{C}$ was distributed to most tissues of injected rats. Amounts of ${ }^{14} \mathrm{C}$ in corresponding tissues of gavaged male and female mice were similar; except for blood and kidney. More ${ }^{14} \mathrm{C}$ was distributed to these two tissues in male mice. No differences in amounts of ${ }^{14} \mathrm{C}$ in corresponding tissues of gavaged and injected male mice were detected. Although values for similar tissues were within the same order of magnitude, differences were detected between amounts of ${ }^{14} \mathrm{C}$ in some corresponding tissues of rats and mice. The greatest statistical differences were observed between ${ }^{14} \mathrm{C}$ content in adipose tissue and muscle of female rats and mice. Recovery of dose was similar $(79 \pm 5 \%)$ among the gavaged animals represented in Table I $(n=20)$. Lower than expected recovery probably represented under-estimations of muscle, skin, and/or adipose tissue volumes.

Urinary excretion of ${ }^{14} \mathrm{C}$ was minimal for rats and female mice (Table I). Excretion of ${ }^{14} \mathrm{C}$ in urine of male mice was also minimal, but was significantly higher than amounts excreted in rat or female mouse urine. The only radiolabeled peak detected by HPLC in the urine of a gavaged male mouse was parent chemical (not shown). There were no differences in the amount of ${ }^{14} \mathrm{C}$ excreted in feces among gavaged treatment groups. Recovery of radioactivity in solvent washes of $0-24 \mathrm{~h}$ feces of male rats and mice receiving a single dose of $1 \mu \mathrm{mol} / \mathrm{kg}$ was $93 \pm 3$ and $90 \pm 1 \%$, respectively. No metabolites of BDE153 were detected in these feces extracts.

Excretion of ${ }^{14} \mathrm{C}$ over time and amounts remaining in tissues 10 days after administration of a single dose of $1 \mu \mathrm{mol} / \mathrm{kg}$ by gavage to male rats $(\mathrm{n}=5)$ were determined. A total of $45 \pm 5 \%$ of a single dose of $1 \mu \mathrm{mol} / \mathrm{kg}$ was excreted in feces over 10 days, almost all in the first two days following dosing. Cumulative excretion of ${ }^{14} \mathrm{C}$ in urine amounted to $0.1 \pm 0.0 \%$ of the total dose. Tissues containing greater than $1 \%$ of the cumulative dose 10 days after administration were adipose $(32 \pm 3 \%)$, skin $(8 \pm 1 \%)$, and muscle $(5 \pm 2 \%)$.

Dose-response characteristics were investigated in male rats receiving single doses of 1,10 , and $100 \mu \mathrm{mol} \mathrm{BDE} 153 / \mathrm{kg}$ by gavage (Table II). Generally, concentrations of ${ }^{14} \mathrm{C}$ in tissues 24 $\mathrm{h}$ after BDE153 administration appeared to increase proportionally to the increase in dose (compare columns 1, 4, and 5 of Table II). However, statistical analysis of the data indicated higher than expected concentrations of BDE153 equivalents in blood, adipose, skin, lung, and brain in rats receiving $100 \mu \mathrm{mol} / \mathrm{kg}$ over those of rats receiving $1 \mu \mathrm{mol} / \mathrm{kg}$. Adrenal contained the greatest concentration of ${ }^{14} \mathrm{C}$ of any tissue with respect to dose, followed in order by adipose tissue and liver. Excretion of ${ }^{14} \mathrm{C}$ by rats was proportional to dose for all three treatment groups (not shown). Rats excreted $32 \pm 6,31 \pm 5$, and $31 \pm 8 \%$ dose in feces $0-24 \mathrm{~h}$ after administration of either 1,10 , or $100 \mu \mathrm{mol} / \mathrm{kg}$, respectively. Further, the $\%$ dose excreted in $0-24 \mathrm{~h}$ urine of rats receiving either 10 or $100 \mu \mathrm{mol} / \mathrm{kg}$ was identical to that excreted by rats receiving $1 \mu \mathrm{mol} /$ $\operatorname{kg}(0.1 \pm 0.0)$.

BDE153-derived radioactivity accumulated in all tissues examined following multiple dosing (compare columns 1, 2, and 3 of Table II). However, normalization of the data indicated less than expected concentrations of ${ }^{14} \mathrm{C}$ in blood, liver, kidney, lung, brain and adrenal of rats receiving $1 \mu \mathrm{mol} / \mathrm{kg}$ for 10 days. In contrast, adipose tissue and skin contained higher concentrations of ${ }^{14} \mathrm{C}$ than expected after repeated doses. Repeated administration of BDE153 did not appreciably affect excretion of BDE153-derived radioactivity in urine or feces over time (data not shown). 
Greater than $99 \%$ of the radiolabel of a prepared mixture of PBDEs was recovered from adipose tissue $24 \mathrm{~h}$ after 1 or 3 doses using three successive washes of 95:5 hexane/isoamyl alcohol.

No PBDE metabolites were detected in this tissue. Results presented in Table II for BDE153 and for BDE47 and BDE99 presented elsewhere (Sanders et al. 2006; Chen et al. 2006b), demonstrated an increase in concentrations of all three PBDEs in adipose tissue and liver over time following repeated dosing with the individual congeners. However, relative to each other, concentrations of BDE47 increased, BDE99 decreased, and BDE153 remained constant in adipose tissue over time when administered together (Table III). BDE153 had the greatest distribution to liver $24 \mathrm{~h}$ following one dose of the mixture (Table III). Concentrations of BDE153 remained higher than either BDE47 or BDE99 in liver after three doses.

Concentrations of BDE99 in liver were similar to those of BDE47 after one dose, but were one-half those of BDE47 after three doses. Recovery of ${ }^{14} \mathrm{C}$ from liver $24 \mathrm{~h}$ after one dose of the mixture was similar to that after three doses ( $89 \pm 3$ and $88 \pm 2 \%$, respectively). In contrast, a major difference from each of these values was observed for recovery of ${ }^{14} \mathrm{C}$ from liver of rats dosed with BDE99 alone, but not BDE47 or BDE153. Total recovery of ${ }^{14} \mathrm{C}$ from liver 24 $\mathrm{h}$ after one and three doses of BDE47 only, was $94 \pm 1$, and $88 \pm 1 \%$, respectively. Total recovery of ${ }^{14} \mathrm{C}$ from liver $24 \mathrm{~h}$ after one and three doses of BDE153 only, was $85 \pm 1$ and 94 $\pm 1 \%$, respectively. However, only $56 \pm 3$ and $48 \pm 8 \%$ of the ${ }^{14} \mathrm{C}$ was recovered after one and three doses from liver of rats receiving BDE99 alone. Hexane:isoamyl alcohol extracted most, if not all, parent PBDEs from lipid; therefore, the majority of the residual ${ }^{14} \mathrm{C}$ in liver was believed to be polar metabolites and/or metabolites covalently bound to macromolecules. In liver of rats receiving BDE99 alone, most of the residual radioactivity was recovered in methanol, and of this, about $85 \%$ was characterized by HPLC as metabolic products. Unextracted radioactivity was considered to be covalently bound to liver protein. This amounted to $3.5 \pm 0.8$ and $9.1 \pm 3.4$ pmol of BDE99 equivalents bound to each $\mathrm{mg}$ of protein after one and three doses, respectively.

Radioactivity was extracted from feces collected $24 \mathrm{~h}$ following each dose of the PBDE mixture and analyzed by HPLC. After one dose, $87 \pm 3 \%$ of the total radioactivity in feces was recovered and of that amount, $96 \pm 1 \%$ was characterized as starting material (Figure 2, panel A). After three doses, ${ }^{14} \mathrm{C}$ recovery dropped to $61 \pm 4 \%$ and of that amount, $68 \pm 4 \%$ consisted of parent PBDEs (Figure 2, panel B). Metabolic products in feces collected 0-24 h following the last of 3 doses of the mixture appeared to primarily arise from BDE99 metabolism, based on observations of corresponding metabolites in feces of rats receiving three doses of BDE99 alone (Figure 2, panel C). In contrast, negligible amounts of metabolic products were detected in feces of rats receiving either BDE47 or BDE153 alone after 3 doses (data not shown).

\section{Discussion}

BDE153 was the least absorbed of the three PBDEs used in the present studies (ca. 70\% in rats and mice). Administration of an equimolar dose of BDE47 resulted in ca. $75 \%$ absorption in rats and $85 \%$ in mice (Sanders et al. 2006). Approximately 85\% of a similar dose of BDE99 was absorbed in either rats or mice (Chen et al. 2006b). Thus, absorption and exposure data would indicate less distribution of BDE153 to mammalian tissues, relative to the other two PBDEs. However, differences in lipophilicity and extent of metabolism of the individual congeners can lead to relatively higher (or lower) than expected levels of the PBDEs, including BDE153, in some tissues as discussed below.

Sex-related differences were observed in tissue distribution of BDE153-derived radioactivity in gavaged animals (Table I). However, because most of these differences were only marginally significant, they are thought to be biologically insignificant. A notable exception was adipose tissue, where female mice contained a higher amount of ${ }^{14} \mathrm{C}$ than did female rats. This difference was confirmed by body weight-independent data ( $1.3 \pm 0.3$ vs. $2.9 \pm 0.6 \mathrm{nmol}$ 
equivalents/g for rat and mouse, respectively). The reason for this difference is uncertain. Only one statistically significant difference was detected in excretion data derived from gavaged animals. Male mice excreted slightly more ${ }^{14} \mathrm{C}$ in urine than did the other animals. However, the difference probably had little or no biological significance, given the negligible amount of ${ }^{14} \mathrm{C}$ excretion in urine of all groups. Together, the disposition data indicate similar in vivo fates for BDE153 in male and female rats and mice following oral administration.

Statistically significant differences were detected when dose-response and multiple dosing tissue distribution data for male rats (Table II) were normalized to the single dose of $1 \mu \mathrm{mol} /$ $\mathrm{kg}$, indicating dose-independent concentrations of ${ }^{14} \mathrm{C}$ in some tissues among some treatment groups. However, the overall trends of ${ }^{14} \mathrm{C}$ tissue distribution and excretion support doseproportionally in this range. Interpretation of the data derived from repeated dosing was more ambiguous. The tissue burdens of ${ }^{14} \mathrm{C}$ increased in all cases, but were variable among tissues with regards to proportionality of the data. Results indicated that $50 \%$ or more of a single oral dose of BDE153 to rats remained in tissues, primarily adipose, 10 days after administration. Therefore, the whole body half-life of BDE153, much longer than the dosing interval for repeated administration, probably influenced effects on disposition, e.g. redistribution of ${ }^{14} \mathrm{C}$ from individual doses.

The in vivo fate of BDE153 quantitatively differs from that of BDE47 and BDE99 in rodents. In the present study, male rats excreted only a trace of BDE153-derived radioactivity in bile, all as parent chemical; whereas, after administration of similar doses, excretion of BDE47- and BDE99-derived radioactivity was greater in bile and mostly consisted of metabolic products (Sanders et al. 2006; Chen et al. 2006b). In turn, BDE99-treated rats excreted greater amounts of metabolic products in bile (and in urine) than did BDE47-treated rats. Therefore, a conclusion can be made that BDE99 undergoes the most, and BDE153 undergoes the least metabolism of the three congeners in the rat.

Rats and mice excreted very little ${ }^{14} \mathrm{C}$ in urine following single dose administration of BDE153; only about $1 \%$ of $1 \mu \mathrm{mol} / \mathrm{kg}$ was excreted in urine of gavaged male mice. This is in stark contrast to the \% dose excreted in urine of BDE47- and BDE99-treated mice. Upwards of 40\% of $1 \mu \mathrm{mol} / \mathrm{kg}$ of BDE47 and 10\% of a similar dose of BDE99 were excreted as starting material in urine (Sanders et al. 2006; Chen et al. 2006b). Male mice consistently excreted more of each congener in urine than did female mice following gavage (although some differences weren't statistically significant). Given the limited water solubility of PBDEs, it is probable that one or more mouse-specific carrier proteins are responsible for excretion of parent PBDEs in urine. These putative carrier(s), probably major urinary proteins (MUPs), are obviously affected by bromine content and are more prevalent in the male mouse. MUPs bind odorant molecules used for chemosensory signaling among rodents (reviewed in Cavaggioni and MucignatCaretta 2000).

Quantitative differences in the fates of BDE47, BDE99, and BDE153 were evident when the three congeners were administered together in equimolar doses to rats. Relative to each other, BDE47 accumulated to a greater extent in adipose tissue, whereas BDE153 accumulated to a greater extent in liver (Table III). Explanations for these observations can be made based on comparison of these data with those compiled following administration of individual congeners alone. First, much of the ${ }^{14} \mathrm{C}$ in liver of BDE99-treated rats consisted of metabolic products, produced upon "first pass" to the tissue following oral administration. BDE47 also undergoes metabolism, but not as much as BDE99; therefore, relative to BDE99, more BDE47 should be available to sequester both in liver and in adipose tissue. BDE153 would be expected to have a larger $K_{\mathrm{Ow}}$ than either BDE47 or BDE99 (Hardy 2004); therefore, BDE152 should accumulate to a greater extent in lipid of liver and other tissues upon administration of equimolar doses of the PBDEs. In fact, a comparison of data presented here, in Sanders et al. 
(2006), and in Chen et al. (2006b) from animals receiving repeated doses of $1 \mu \mathrm{mol} / \mathrm{kg}$ of the individual congeners, demonstrated higher levels of BDE153 in most tissues, with adipose tissue being a notable exception. In the present PBDE mixture study, relatively higher concentrations of BDE153 observed in liver may be explained by the sequestration of BDE153 in lipid upon "first pass" exposure, followed by slow clearance from the tissue due to minimal metabolism. Further, the possibility of selective binding of BDE153 to liver components such as CYP2B and/or CYP3A, effectively increasing its half-life in the tissue, has not been determined. The contradictory observation of relatively lower BDE153 concentrations in adipose tissue following administration of the PBDE mixture may be due to greater retention of BDE153 in liver and other well-perfused tissues. Consequently, less BDE153 would be available to sequester in poorly-perfused adipose tissue.

A meta-analysis of concentrations of PBDEs in extracted lipid from human samples (milk and tissues, including blood) collected from 1970 to 2002 demonstrated a ratio of BDE47, BDE99, and BDE153 of ca. 5:1:1 (Hites 2004). This ratio dramatically differs from the ratio of these congeners in commercial mixtures, e.g. 12:14:1 for the DE71 used in studies in our laboratory (Sanders et al. 2005). In the present study, the ratio of the congeners in adipose tissue of rats receiving equimolar amounts of the PBDEs by gavage was ca. 2:1:1 after three doses (see Table III), similar to that observed in human lipid. This suggests that, following exposure, distribution of all three congeners to adipose tissue may be similar in rats and humans. Further, it could be speculated that humans metabolize BDE99, based on evidence presented here that the ratio of BDE47 to BDE99 in adipose tissue of mixture-treated rats was metabolism-dependent.

Minimal metabolism of BDE153 in rodents observed in these studies was not totally unexpected. Metabolism of PCBs most readily occurs at sites with two adjacent unsubstituted carbons (Matthews and Dedrick 1984) and the same probably holds true for PBDEs. Adjacent unsubstituted carbons are available for metabolism on both the BDE47 and BDE99 molecules, but not BDE153. Metabolic pathways are similar for BDE47 and BDE99 in the rat, proceeding through formation of potentially reactive arene oxides catalyzed by cytochromes P450 (CYPs) in the liver (Sanders et al. 2006; Chen et al. 2006b). Reactivity of BDE99 metabolite(s) was indicated with the observation of apparent covalent binding of ${ }^{14} \mathrm{C}$ with liver protein in rats dosed with BDE99. Further, covalent binding appeared to be linear with dose. Most metabolites of BDE47 and BDE99 were eliminated in bile and excreted in feces (Sanders et al. 2006; Chen et al. 2006b). As shown in Figure 2, excretion of PBDE metabolites in feces increased over time following repeated administration of the radiolabeled mixture, suggesting possible induction of metabolism, particularly for BDE99. BDE47, BDE99, and BDE153 apparently activate the constitutive androstane receptor (CAR) in the rat, due to their abilities to upregulate $C Y P 2 B$ gene expression (Sanders et al. 2005). BDE47 and BDE99 also appear to be substrates for CYP2B (Meerts et al. 2000); therefore, may induce their own metabolism upon repeated exposure. BDE153 was poorly metabolized in these studies, therefore is probably a poor substrate for CYP2B; however, as an inducer of CYP2B (in the $\mathrm{mg} / \mathrm{kg}$ range) would probably affect the metabolism of both BDE47 and BDE99. Most of the metabolic products detected in feces of rats treated with the radiolabeled PBDE mixture for three days apparently originated from BDE99 metabolism. Further, quantitatively more BDE99 metabolites were present after administration of $1 \mu \mathrm{mol} / \mathrm{kg}$ of BDE99 in a mixture than when administered alone (compare panels B and C of Figure 2). Additive induction of CYP2Bs by BDE47, BDE99, and BDE153 probably accounted for this effect.

As for potential toxicity, neither BDE153, BDE47, nor BDE99 appear to be dioxin-like in rodents. Tissue distribution data indicated that these PBDEs have a liver to fat ratio more in line with that of non-coplanar PCBs, such as 2,2',4,4',5,5'-hexaCB (PCB153), rather than dioxin-like PCBs such as 3,3',4,4',5-pentaCB (PCB126) (Lyche et al. 2004). This is not surprising, since BDE47, BDE99, and BDE153 are non-coplanar and have little or no apparent 
ability to induce CYP1Al gene expression, as does PCB126 (Sanders et al. 2005). Conversely, all three congeners induce $C Y P 2 B$ gene expression in a similar fashion to PCB153. Some mechanisms of toxicity, such as disruption of thyroid hormone homeostasis in rodents are probably shared by non-coplanar PCBs and the lower molecular weight PBDEs. However, this mode of action as mediated by PB-like enzyme inducers at relatively high doses is thought not to be relevant to humans (McClain 1995). Results presented here and from previous work conducted in our laboratory demonstrate that biotransformation pathways for BDE47 and BDE99 potentially produce reactive intermediates possibly associated with some toxic responses previously observed in rats. BDE153 on the other hand, probably doesn't generate much, if any, reactive products in the rat (or mouse); therefore, toxicity associated with BDE153 exposure may better correlate with induction of enzymes such as CYP2B and/or disruption of cellular membrane integrity mediated by the parent chemical.

The relevance of rodent studies of BDE153 and other PBDEs in assessment of risk to humans should be evaluated with care, particularly regarding metabolism of these chemicals.

Metabolism and induction of PBDEs appear to be a "first pass" phenomenon; therefore, the dose may be more critical to toxicity than total exposure over time. That is, once the majority of a PBDE dose is sequestered in adipose tissue, little is available for further metabolism or enzyme induction that could influence toxicity. Further, the extent of PBDE metabolism in humans, exposed to lower concentrations of PBDEs in the environment, may differ from rodents generally exposed to higher concentrations in experimental studies. Finally, potential species-specific differences in activation of CAR and/or the pregnane X receptor (PXR) by PBDEs and differences in substrate specificity between human and rodent CYPs may affect rates and routes of PBDE metabolism. However, regardless of toxicity, the accumulation of any xenobiotic in humans is a concern that may over-ride any uncertainties in extrapolation of results from rodents to humans.

\section{Acknowledgments}

The authors wish to thank Mr. A.C. Creech for excellent technical assistance. Thanks also go to Drs, D. Shea, R. Rose, A. Wallace, and C. Hofelt of the Department of Environmental and Molecular Toxicology, North Carolina State University, for helpful discussions concerning these studies. This research was supported by the Intramural Research Program of the NIH and NIEHS.

\section{References}

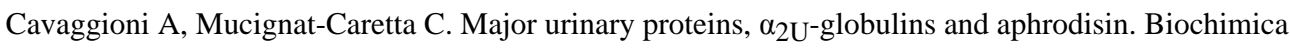
et Biophysica Acta 2000;1482:218-228. [PubMed: 11058763]

Chen L-G, Mai B-X, Bi X-H, Chen S-J, Wang X-M, Ran Y, Luo X-J, Sheng G-Y, Fu J-M, Zeng EY. Concentration levels, compositional profiles, and gas-particle partitioning of polybrominated diphenyl ethers in the atmosphere of an urban city in south China. Environmental Science and Technology 2006a;40:1190-1196. [PubMed: 16572774]

Chen L-J, Lebetkin EH, Sanders JM, Burka LT. Metabolism and disposition of 2,2'4,4',5pentabromodiphenyl ether (BDE99) following single or repeated administration to rats and mice. Xenobiotica. $2006 \mathrm{~b}$ (in press).

de Wit CA. An overview of brominated flame retardants in the environment. Chemosphere 2002;46:583624. [PubMed: 11999784]

Fowles JR, Fairbrother A, Baecher-Steppan L, Kerkvliet NI. Immunologic and endocrine effects of the flame-retardant pentabromodiphenyl ether (DE71) in C57BL/6J mice. Toxicology 1994;86:49-61. [PubMed: 8134923]

Hardy ML. A comparison of the fish bioconcentration factors for brominate flame retardants with their nonbrominated analogues. Environmental Toxicology and Chemistry 2004;23:656-661. [PubMed: 15285359] 
Hites RA. Polybrominated diphenyl ethers in the environment and in people: A meta-analysis of concentrations. Environmental Science and Technology 2004;38:945-956. [PubMed: 14998004]

Lyche JL, Skaare JU, Larsen HJS, Ropstad E. Levels of PCB 126 and PCB 153 in plasma and tissues in goats exposed during gestation and lactation. Chemosphere 2004;55:621-629. [PubMed: 15006515]

Matthews HB, Dedrick RL. Pharmacokinetics of PCBs. Annual Review of Pharmacology and Toxicology 1984;24:85-103.

McClain RM. Mechanistic considerations for the relevance of animal data on thyroid neoplasia to human risk assessment. Mutation Research 1995;333:131-142. [PubMed: 8538620]

McDonald TA. Polybrominated diphenyl ether levels among United States residents: Daily intake and risk of harm to the developing brain and reproductive organs. Integrated Environmental Assessment and Management 2005;1:343-354. [PubMed: 16639901]

Meerts IATM, van Zanden JJ, Luijks EAC, van Leeuwen-Bol I, Marsh G, Jakobsson E, Bergman Å, Brouwer A. Potent competitive interactions of some brominated flame retardants and related compounds with human transthyretin in vitro. Toxicological Sciences 2000;56:95-104. [PubMed: 10869457]

Meironyté D, Norén K, Bergman Å. Analysis of polybrominated diphenyl ethers in Swedish human milk. A time-related trend study, 1972-1997. Journal of Toxicology and Environmental Health, Part A 1999;58:329-341. [PubMed: 10580757]

Sanders JM, Burka LT, Smith CS, Black W, James R, Cunningham ML. Differential expression of $C Y P 1 A, 2 B$, and $3 A$ genes in the F344 rat following exposure to a polybrominated diphenyl ether mixture or individual components. Toxicological Sciences 2005;88:127-133. [PubMed: 16107549]

Sanders JM, Chen L-J, Lebetkin EH, Burka LT. Metabolism and disposition of 2,2',4,4'tetrabromodiphenyl ether following administration of single or multiple doses to rats and mice. Xenobiotica 2006;36:103-117. [PubMed: 16507516]

Sjödin A, Jakobsson E, Kierkegaard A, Marsh G, Sellström U. Gas chromatographic identification and quantification of polybrominated diphenyl ethers in a commercial product, Bromkal 70-5DE. Journal of Chromatography 1998;822:83-89.

Sjödin A, Jones RS, Focant J-F, Lapeza C, Wang RY, McGahee EE, Zhang Y, Turner WE, Slazyk B, Needham LL, Patterson DG. Retrospective time-trend study of polybrominated diphenyl ether and polybrominated and polychlorinated biphenyl levels in human serum from the United States. Environmental Health Perspectives 2004;112:654-658. [PubMed: 15121506]

von Meyerinck L, Hufnagel B, Schmoldt A, Benthe HF. Induction of rat liver microsomal cytochrome P-450 by the pentabromo diphenyl ether Bromkal 70 and half-lives of its components in the adipose tissue. Toxicology 1990;61:259-274. [PubMed: 2330598]

Zhou T, Ross DG, DeVito MJ, Crofton KM. Effects of short-term in vivo exposure to polybrominated diphenyl ethers on thyroid hormones and hepatic enzyme activities in weanling rats. Toxicological Sciences 2001;61:76-82. [PubMed: 11294977]

Zhou T, Taylor MM, DeVito MJ, Crofton KM. Developmental exposure to brominated diphenyl ethers results in thyroid hormone disruption. Toxicological Sciences 2002;66:105-116. [PubMed: 11861977] 




Figure 1.

Representative HPLC (system \#1) chromatogram of the commercial flame retardant DE71. Peaks 1, 2, and 3 contain BDE47, BDE99, and BDE153, respectively. 




Figure 2.

Representative HPLC (system \#2) chromatograms of ${ }^{14} \mathrm{C}$ recovered from feces of rats receiving PBDEs by gavage. A) 0-24 h feces after 1 dose of a mixture of $1 \mu \mathrm{mol} / \mathrm{kg}$ each of BDE47, BDE99, and BDE153. B) 0-24 h feces after 3 doses of the mixture. C) 0-24 h feces after 3 doses of BDE99 alone. Peaks 1, 2, and 3 are BDE47, BDE99, and BDE153, respectively. 





Table III

Relative \% total peak areas of three PBDEs from HPLC chromatograms of ${ }^{14} \mathrm{C}$ recovered from male rat tissues $24 \mathrm{~h}$ following daily administration of a mixture of $1 \mu \mathrm{mol} / \mathrm{kg}$ of each congener.

\begin{tabular}{rcccc}
\hline & Daily doses & BDE47 & BDE99 & BDE153 \\
Mixture $^{a}$ & & $36 \pm 0$ & $36 \pm 1$ & $29 \pm 1$ \\
Adipose & 1 & $46 \pm 3^{b}$ & $32 \pm 2$ & $22 \pm 3$ \\
Liver & 3 & $51 \pm 2$ & $26 \pm 1$ & $23 \pm 1$ \\
& 1 & $19 \pm 2$ & $18 \pm 2$ & $63 \pm 3$ \\
\hline
\end{tabular}

\footnotetext{
${ }^{a}$ Data are the mean \pm SD of relative peak areas of the PBDEs following three injections of the dosing solution into the HPLC system.

${ }^{b}$ Values are the mean \pm SD for one injection each of solvent extracts of tissue from 4-5 rats/group.
} 